\title{
Short-term overfeeding induces insulin resistance in weight-stable patients after bariatric surgery
}

Citation for published version (APA):

Nijhuis, J., van Dielen, F. M., Schaper, N., Wiebolt, J., Koks, A., Prakken, F. J., Rensen, S. S. M., Buurman, W. A., \& Greve, J. W. (2008). Short-term overfeeding induces insulin resistance in weight-stable patients after bariatric surgery. Obesity Surgery, 18(3), 300-5. https://doi.org/10.1007/s11695-007-9306-9

Document status and date:

Published: 01/01/2008

DOI:

10.1007/s11695-007-9306-9

Document Version:

Publisher's PDF, also known as Version of record

Document license:

Taverne

Please check the document version of this publication:

- A submitted manuscript is the version of the article upon submission and before peer-review. There can be important differences between the submitted version and the official published version of record.

People interested in the research are advised to contact the author for the final version of the publication, or visit the DOI to the publisher's website.

- The final author version and the galley proof are versions of the publication after peer review.

- The final published version features the final layout of the paper including the volume, issue and page numbers.

Link to publication

\footnotetext{
General rights rights.

- You may freely distribute the URL identifying the publication in the public portal. please follow below link for the End User Agreement:

www.umlib.nl/taverne-license

Take down policy

If you believe that this document breaches copyright please contact us at:

repository@maastrichtuniversity.nl

providing details and we will investigate your claim.
}

Copyright and moral rights for the publications made accessible in the public portal are retained by the authors and/or other copyright owners and it is a condition of accessing publications that users recognise and abide by the legal requirements associated with these

- Users may download and print one copy of any publication from the public portal for the purpose of private study or research.

- You may not further distribute the material or use it for any profit-making activity or commercial gain

If the publication is distributed under the terms of Article $25 \mathrm{fa}$ of the Dutch Copyright Act, indicated by the "Taverne" license above, 


\title{
Short-term Overfeeding Induces Insulin Resistance in Weight-stable Patients After Bariatric Surgery
}

\author{
Jeroen Nijhuis - Francois M. H. van Dielen • \\ Nicolaas C. Schaper • Janneke Wiebolt • Afra Koks • \\ Fred J. Prakken - Sander S. M. Rensen • \\ Wim A. Buurman • Jan Willem M. Greve
}

Received: 13 August 2007 / Accepted: 29 September 2007 / Published online: 16 January 2008

(C) Springer Science + Business Media B.V. 2007

\begin{abstract}
Background Short time overfeeding of rats rapidly leads to insulin resistance (IR). A study with healthy human volunteers, which we suggest are less susceptible for developing IR after short time overfeeding, did not show these effects on IR. Therefore a study population of weightstable, former morbidly obese subjects (BMI $31.3 \mathrm{~kg} / \mathrm{m}^{2}$ ), which were treated with bariatric surgery approximately 3 years ago was selected.

Methods Eleven subjects were submitted to a 7-day overfeeding study, resulting in a $53 \%$ increase in caloric intake $(1,227 \pm 394.4$ to $1,879.2 \pm 298.4 \mathrm{kcal} /$ day $)$. During normal diet and after overfeeding, insulin sensitivity was measured using steady state plasma glucose (SSPG) levels. At these time points, BMI and waist/hip ratio together with plasma levels of inflammatory markers (CRP, AGP, LBP, and TNF- $\alpha$ receptors) and plasma leptin values were also measured.

Results SSPG levels after overfeeding increased from $8.2 \pm$ 3.2 to $10.6 \pm 2.6 \mathrm{mmol} / 1(P<0.05)$, indicating decreased insulin sensitivity after overfeeding. Fasting plasma insulin, glucose, circulating levels of inflammatory markers, BMI, and waist/hip ratio remained unchanged.
\end{abstract}

J. Nijhuis · F. M. H. van Dielen · J. Wiebolt • A. Koks • F. J. Prakken · S. S. M. Rensen $(\bowtie) \cdot$ W. A. Buurman • J. M. Greve

Nutrition and Toxicology Research Institute Maastricht (NUTRIM), Department of General Surgery,

Maastricht University/University Hospital Maastricht, P.O. Box 616, 6200 MD Maastricht, The Netherlands e-mail: s.rensen@ah.unimaas.nl

N. C. Schaper

Nutrition and Toxicology Research Institute Maastricht (NUTRIM), Department of Internal Medicine, Maastricht University/University Hospital Maastricht,

Maastricht, The Netherlands
Conclusions This study shows that overfeeding in a group of weight-stable, former morbidly obese subjects 3 years after bariatric surgery results in decreased insulin sensitivity. The mechanisms behind decreased insulin sensitivity induced by overfeeding are poorly understood, but the present results reveal that a unique human model is available to study these mechanisms, leading to a better understanding of the pathophysiology of IR.

Keywords Insulin sensitivity $\cdot \mathrm{SSPG} \cdot$ Overfeeding

\section{Introduction}

The mechanisms that underlie insulin resistance in morbid obesity are in part unravelled. Increased fat mass and accumulation of fat in organs pivotal to glucose metabolism are thought to play a role. Moreover, the low-grade inflammatory condition associated with morbid obesity is also considered to be central to the pathophysiology of insulin resistance in morbid obesity [1].

Recently, increased food intake accompanying morbid obesity is also considered to be involved. Rats subjected to an overfeeding diet were shown to develop insulin resistance within 7 days [2]. However, a study with human volunteers failed to show this effect of overfeeding on insulin sensitivity [3]. Selection of the study population could be the cause of the discrepancy between these studies. The population selected consisted of physically active healthy men with a mean BMI of $21.5 \mathrm{~kg} / \mathrm{m}^{2}$. We considered that such normal weight subjects have sufficient buffer capacity to cope with increased food intake.

Therefore, to investigate the effect of overfeeding on insulin sensitivity, a study population was selected consisting of former morbidly obese patients treated with bariatric 
surgery. These weight-stable subjects are still mildly obese and had developed insulin resistance in the past while being morbidly obese, which subsided after surgery [4].

\section{Research Design and Methods}

Eleven consecutive subjects were included, two males and nine females. These subjects were on average 3.4 years after their surgical treatment for morbid obesity. Nine patients underwent vertical banded gastroplasty and two patients received a Lap-Band, both gastric restrictive procedures. At the moment of the experiment, all subjects had reached a stable body weight for at least 1 year. The subjects were healthy according to history, clinical examination, and routine laboratory tests. In particular, none of the studied subjects had evidence of diabetes mellitus or inflammatory disease or were taking medication known to influence glucose metabolism. Characteristics of the study population are presented in Table 1. The study was approved by the ethical committee of the University Hospital Maastricht, The Netherlands. All subjects gave written informed consent.

\section{Steady State Plasma Glucose Measurement}

Insulin sensitivity was determined by using steady state plasma glucose (SSPG) levels, described by Reaven and colleagues $[5,6]$. This insulin suppression test determines SSPG concentration as a measure for insulin-mediated glucose uptake and highly correlates $(r>0.90)$ with the golden standard, the hyperinsulinemic euglycemic clamp technique.

Table 1 Characteristics and physiological parameters of the subjects during normal diet and after the overfeeding experiment

\begin{tabular}{lccc}
\hline Variables & $\begin{array}{l}\text { Normal diet } \\
(n=11)\end{array}$ & $\begin{array}{l}\text { After overfeeding } \\
(n=11)\end{array}$ & $P$ value \\
\hline Sex (female/male) & $9 / 2$ & & \\
Age (years) & $39 \pm 18.5$ & & \\
Weight (kg) & $89.0 \pm 18.9$ & $89.8 \pm 19.5$ & NS \\
BMI (kg/m ${ }^{2}$ ) & $31.3 \pm 4.9$ & $31.5 \pm 5.1$ & NS \\
Waist/hip ratio & $0.9 \pm 0.1$ & $0.9 \pm 0.1$ & NS \\
\% EWL & $70 \pm 13.8$ & & \\
Weight loss (kg) & $47 \pm 6.7$ & & \\
Fasting glucose (mmol/l) & $5.5 \pm 0.6$ & $5.5 \pm 0.6$ & $\mathrm{NS}$ \\
Fasting insulin (mU/l) & $4.5 \pm 2.9$ & $4.7 \pm 1.1$ & $\mathrm{NS}$ \\
HOMA-IR & $1.11 \pm 0.55$ & $1.14 \pm 0.30$ & $\mathrm{NS}$ \\
Days after surgery & $1228 \pm 394$ & & \\
Energy intake (kcal/day) & $1227 \pm 394.4$ & $1879.2 \pm 298.4$ & 0.005 \\
Carbohydrate intake & $134.0 \pm 32.3$ & $214 \pm 32.9$ & 0.005 \\
$\quad$ (g/day) & & & \\
Mean arterial pressure & $92.5 \pm 12.9$ & $93.0 \pm 9.9$ & $\mathrm{NS}$ \\
$\quad$ (mmHg) & & & \\
\hline
\end{tabular}

$N S$ : not significant
In short, after a 12 -h overnight fast, body weight and body height were measured. Subjects were studied supine in a hospital bed. Catheters were placed in both antecubital veins to enable infusion of glucose, insulin, and octreotide as well as venous blood sampling. During an acclimatization period of $30 \mathrm{~min}$, automatic blood pressure measurement (Dinamap, Criticon, Tampa, FL, USA) was performed. Octreotide (Sandostatin, kindly provided by Novartis Pharma B.V., Arnhem, The Netherlands), a somatostatin analog, was administered intravenously by using a syringe infusion pump (Treonic IP4, Vickers Medical, England) at $5.0 \mu \mathrm{g} / \mathrm{min}$, preceded by a bolus of $25 \mu \mathrm{g}$. A higher infusion rate was used than described by Pei et al. [7], however, in both the measurements during normal diet and measurements after overfeeding, equal octreotide concentrations were used, decreasing the risk of confounding because of high octreotide plasma concentrations. Insulin (Actrapid, Novo-Nordisk, Bagsærd, Denmark) was infused at a rate of $25 \mathrm{mU} / \mathrm{m}^{2} / \mathrm{min}$ by a second syringe pump. Glucose was infused via a volumetric pump (IVAC 591, IVAC Corporation, San Diego, CA, USA) at $240 \mathrm{mU} / \mathrm{m}^{2} / \mathrm{min}$. Before the test and on different time points during the test, venous blood samples were taken. The mean plasma level of glucose at 150, 160, 170, and $180 \mathrm{~min}$ was defined as the SSPG level.

Plasma glucose was determined by a glucose oxidase method (YSI model 2300 Stat, Yellow Springs Industries, Yellow Springs, OH, USA). Blood samples for determining inflammatory mediators and insulin were immediately put on melting ice. Plasma was prepared by centrifugation at $1,400 \times \mathrm{g}$ for $10 \mathrm{~min}$ at $4^{\circ} \mathrm{C}$. The plasma was spun again at $2,700 \times \mathrm{g}$ for $10 \mathrm{~min}$ at $4^{\circ} \mathrm{C}$ and recovered plasma was stored in aliquots at $-80^{\circ} \mathrm{C}$ until measurement.

\section{Study Protocols}

All subjects were studied twice. Six subjects were studied while on their normal diet after gastric restrictive surgery and subsequently after 1 week of additional feeding. In the other five subjects, the inverse sequence was used. To minimize the effects of the first SSPG test on the second, the mean interval between the two tests was 18 days (range 13-24 days).

The feeding supplement consisted of three packets daily of $200 \mathrm{ml}$ liquid nourishment (Resource Energy Drink by Novartis Nutrition, The Netherlands) with a total energy content of $900 \mathrm{kcal}$ containing $113 \mathrm{~g}$ carbohydrates and $35 \mathrm{~g}$ fat per day.

In the week before the SSPG test, subjects were requested to keep a 3-day food intake diary (registration was performed 1,3 , and 5 days before the test) to calculate total energy intake during additional feeding and during their habitual diet. Participants received detailed written and oral instructions on how to fill in the diaries. They were also asked to take the supplement between their usual meals 
to reduce satiety effects and to return all empty packets to evaluate the amount of extra feeding consumed. The nutrient intake from food records was analyzed by using the international food composition tables.

Reagents, Materials, and Assays

Plasma concentrations of soluble TNF- $\alpha$ receptors, leptin, lipopolysaccharid binding protein (LBP), C-reactive protein (CRP), $\alpha_{1}$-acid glycoprotein (AGP), and insulin concentrations were measured using sandwich ELISAs. TNF- $\alpha$ receptors (55 and 75), leptin, LBP, CRP, and AGP were measured as described elsewhere [8]. Plasma insulin concentrations were measured using a commercially available ELISA (Mercodia AB, Uppsala, Sweden).

All plasma samples were measured in the same run, except for plasma insulin concentrations. When plasma concentrations exceeded the upper detection limit of the assay, samples were additionally diluted and analyzed in a separate run with an overlap. The intraassay and interassay coefficients of variance of the assays were smaller than $10 \%$.

\section{Statistical Analysis}

Data were expressed as the mean \pm SD. The Wilcoxon signrank test was used to analyze differences. A $P$ value of $<0.05$ was denoted as statistically significant.

\section{Results}

BMI and Metabolic Parameters of the Study Group

The preoperative BMI of the study population was $47.4 \pm$ $6.4 \mathrm{~kg} / \mathrm{m}^{2}$. At the time of the overfeeding experiment, at approximately 3 years after bariatric surgery, patients had
Fig. 1 SSPI and SSPG levels during the experiment. Because of similar SSPI levels (a), SSPG values of both conditions can be compared. During normal diet, the SSPG values (b) are significantly lower $\left({ }^{*} P<0.05\right)$ than after overfeeding $(8.2 \pm 3.2 \mathrm{vs} 10.6 \pm 2.6 \mathrm{mmol} / \mathrm{l})$ indicating that overfeeding results in decreased insulin sensitivity
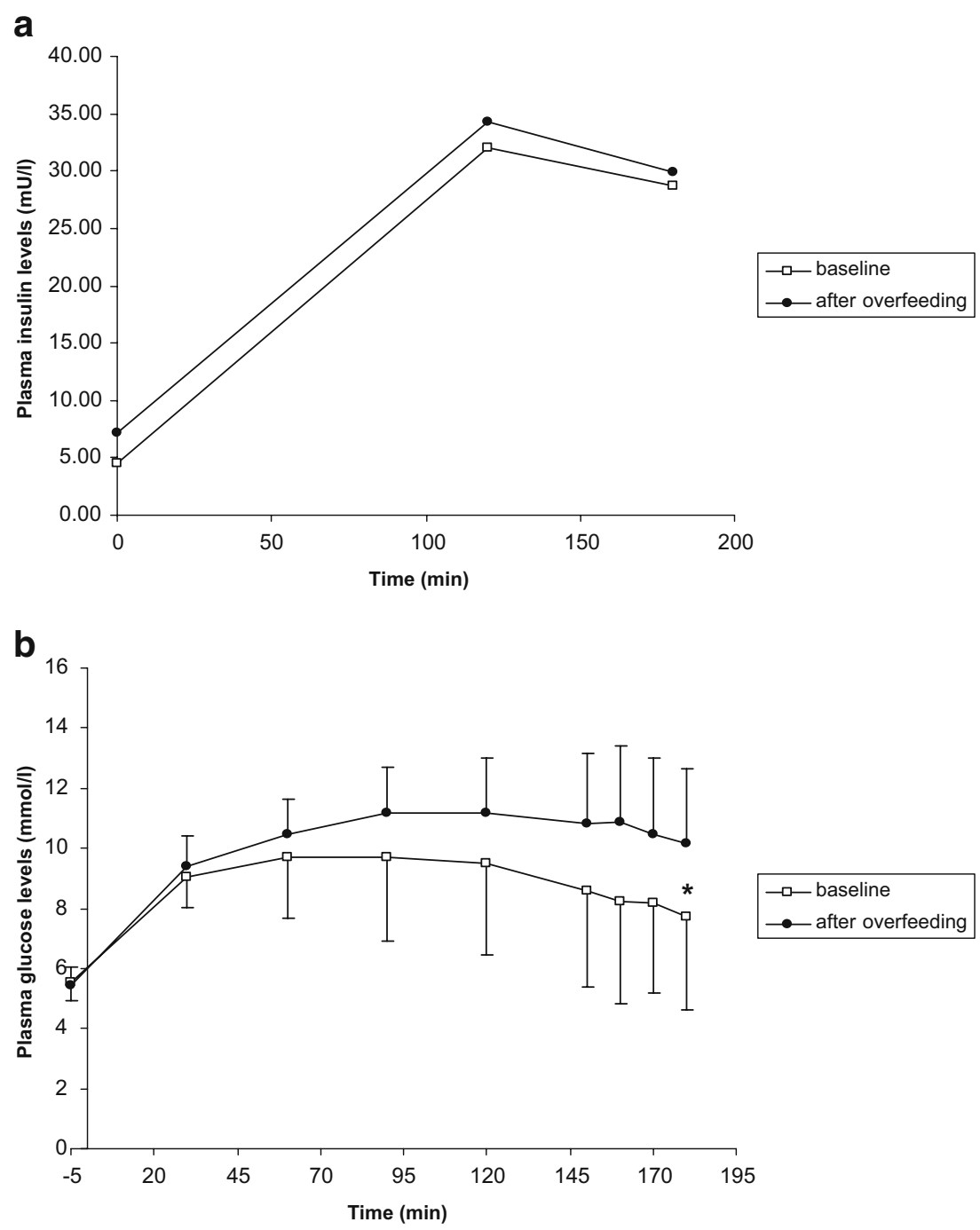
reached a BMI of $31.3 \pm 4.9 \mathrm{~kg} / \mathrm{m}^{2}(70 \%$ excess body weight loss [EWL]). Fasting plasma glucose and insulin levels were within the normal range and did not change after overfeeding. In the year before the overfeeding experiment, the weight remained stable. It is interesting to note that the short period of overfeeding did not lead to a change in body weight or waist/hip ratio.

Effect of Additional Feeding on Insulin Sensitivity in Weight-stable Patients Treated with Restrictive Bariatric Surgery

As shown in Table 1, overfeeding led to a $53 \%$ increase in daily calorie intake and a $59 \%$ increase in carbohydrate intake (both $P=0.005$ ). As assessed by food records, this additional feeding did not lead to changes in other dietary habits (food and liquid intake) in the period of extra food intake.

Figure 1 shows steady state plasma insulin (SSPI) levels and SSPG levels during normal diet and after overfeeding. Because SSPI levels were not different between the two conditions, SSPG levels could be compared during normal diet and after overfeeding. The mean SSPG concentration during normal diet was $8.2 \pm 3.2 \mathrm{mmol} / \mathrm{l}$. SSPG concentrations were significantly higher after a period of overfeeding $(10.6 \pm 2.6 \mathrm{mmol} / \mathrm{l}, P<0.05)$. These data clearly show that insulin sensitivity is reduced by high caloric intake. SSPG levels increased after overfeeding, both in the group subjected to measurements after overfeeding and in the group subjected to measurements before the overfeeding. This implies that the effect of overfeeding on insulin sensitivity is rapidly lost after a short washout period.

It is interesting to note that HOMA-IR, a surrogate marker for insulin sensitivity, remained unchanged after overfeeding.

Table 2 Levels of inflammatory mediators at $t=0$ during the SSPG test of both study groups

\begin{tabular}{lccc}
\hline Variables & $\begin{array}{l}\text { Normal diet } \\
(n=11)\end{array}$ & $\begin{array}{l}\text { After overfeeding } \\
(n=11)\end{array}$ & $P$ value \\
\hline Leptin $(\mathrm{ng} / \mathrm{ml})$ & $15.7 \pm 16.3$ & $18.3 \pm 17.6$ & $\mathrm{NS}$ \\
CRP $(\mu \mathrm{g} / \mathrm{ml})$ & $2.3 \pm 2.2$ & $1.9 \pm 1.3$ & $\mathrm{NS}$ \\
$\mathrm{AGP}(\mathrm{ng} / \mathrm{ml})$ & $10.5 \pm 8.1$ & $8.5 \pm 7.9$ & $\mathrm{NS}$ \\
LBP $(\mu \mathrm{g} / \mathrm{ml})$ & $12.7 \pm 5.2$ & $15.6 \pm 4.4$ & $\mathrm{NS}$ \\
$\begin{array}{l}\text { Soluble TNFR55 } \\
(\mathrm{ng} / \mathrm{ml})\end{array}$ & $0.72 \pm 0.27$ & $0.58 \pm 0.21$ & $\mathrm{NS}$ \\
$\begin{array}{l}\text { Soluble TNFR75 } \\
\quad(\mathrm{ng} / \mathrm{ml})\end{array}$ & $1.26 \pm 0.66$ & $0.98 \pm 0.66$ & $\mathrm{NS}$ \\
& & &
\end{tabular}

Despite decreased insulin sensitivity, inflammatory mediators remained unchanged.

$N S$ : not significant
Analysis of plasma levels of leptin and other inflammatory mediators revealed that overfeeding for 7 days did not affect these parameters (Table 2).

\section{Discussion}

The influence of additional carbohydrate intake (total energy intake of $900 \mathrm{kcal} /$ day) on insulin resistance using SSPG level measurement was assessed in weight-stable patients, 1.5-4.5 years after gastric restrictive surgery. Insulin sensitivity decreased significantly after 1 week of additional feeding. The additional feeding led to a $59 \%$ increase in carbohydrate intake without affecting fasting plasma glucose levels and circulating inflammatory mediators. In addition, no major changes in body weight were observed, showing that increased caloric intake has a strong influence on insulin sensitivity in the population of morbidly obese subjects who have lost a significant amount of weight. These findings emphasize that bariatric surgery should not be considered a temporary intervention but should be implemented life long. A similar study, which shows increased insulin resistance after a 2-week overfeeding regimen, has been performed in Pima Indians [9]. The interesting finding in our study is that, unlike the study in Pima Indians, insulin sensitivity is decreased without weight gain. This shifts the attention toward the effects of macronutrient intake on insulin sensitivity and provides for a unique model to study the effects of macronutrient intake on insulin sensitivity without the confounding effect of weight gain.

Although SSPG levels showed that insulin sensitivity decreased, HOMA-IR failed to show this effect. In this respect, our study also differs from the study in Pima Indians in which fasting insulin levels increased. Unpublished data from our group revealed that this discrepancy between SSPG levels and HOMA-IR values also occurred during the first month after bariatric surgery where SSPG data clearly shows that insulin sensitivity is not decreased, whereas HOMA-IR improved significantly. Metabolic stress, either because of fasting or a caloric challenge, is a common feature in both conditions, which raises the question if HOMA-IR as a surrogate marker for insulin sensitivity can be used during periods of metabolic stress. These findings also give rise to the hypothesis that observed differences between HOMA-IR and SSPG can be accounted for by the storage capacity of the liver for macronutrients. During the first stage of overfeeding, macronutrients are stored in skeletal muscle and adipose tissue. As a result, peripheral insulin sensitivity as measured by SSPG or hyperinsulinemic euglycemic clamp techniques 
decreases. Skeletal muscle cells and adipocytes can still cope with the surplus of macronutrients in the first week of overfeeding and, therefore, the liver is relatively spared during the first week of massive overfeeding leading to normal fasting insulin and glucose plasma levels.

Several mechanisms have been proposed to underlie insulin sensitivity in obese individuals. Currently, research mainly focuses on increased fat mass and accompanying changes in adipocytokine secretion and inflammation. It is interesting to note that the induction of insulin resistance by overfeeding did not result in increased plasma levels of acute phase proteins and the TNF- $\alpha$ receptors, showing that insulin sensitivity can decrease without overt changes in inflammatory parameters, normally closely correlated to insulin resistance. The results of the present study show that, in the absence of inflammation, increased nutrient intake (caloric challenge) could also play a role in the pathophysiology of obesity-induced insulin resistance. One of the processes thought to play a major role in overfeeding-induced insulin resistance is oxidative stress. Recently, it was reported that a single glucose and fat challenge could induce oxidative stress in man [10-12]. In line with this, oxidative stress has recently been shown to be a causative factor in the pathophysiology of insulin resistance [13].

Recently, ER stress and the unfolded protein response have also been linked to IR and obesity. Obesity is thought to increase the metabolic workload for cells, resulting in the accumulation of reactive oxygen species and intermediary metabolites, which activate the unfolded protein response $[14,15]$. Activation of the serine kinase c-Jun aminoterminal kinase (JNK1) induced by ER stress suppresses insulin signaling [16]. Although it has been shown that obesity and oxidative stress can lead to ER stress, no studies have shown a direct effect of overfeeding on ER stress; therefore, studies are needed to unravel the role of ER stress in overfeeding-induced insulin resistance.

Plasma levels of the satiety hormone leptin also remained unchanged, whereas reported data shows increased levels of leptin after overfeeding [2, 17]. Leptin acts as an adipostat and although the study population substantially increases its caloric intake, the total amount of calories is still below average $(1,879 \mathrm{kcal} /$ day $)$, which consequently does not lead to a rise in plasma leptin levels.

It is interesting to note that the present and the study in Pima Indians [9] show decreased insulin sensitivity after overfeeding, whereas an overfeeding study in normal weight, physically active, healthy controls did not result in insulin resistance [3]. A reason for this difference could be the genetic background and/or metabolic alterations of the study population. For the present study, former morbidly obese individuals in the stable weight phase after bariatric surgery were included. This population was known to suffer from insulin resistance before surgery, which was significantly improved at the time stable weight was achieved [18]. Compared to normal weight healthy controls, this population could be metabolically altered, possibly under genetic control, during the process of becoming morbidly obese, resulting in an altered response to overfeeding. Moreover, this population is still obese and, therefore, has an increased risk of developing insulin resistance. To clarify the difference between the response to overfeeding in both groups, further studies are needed.

In conclusion, the present study shows that increased food intake (caloric challenge) in the stable weight phase after bariatric surgery leads to decreased insulin sensitivity without weight gain. This implies that a unique human model is available to study the mechanisms behind insulin resistance induced by overfeeding without the confounding effect of weight gain.

\section{References}

1. Cottam DR, Mattar SG, Barinas-Mitchell E, et al. The chronic inflammatory hypothesis for the morbidity associated with morbid obesity: implications and effects of weight loss. Obes Surg. 2004;14:589-600.

2. Wang J, Obici S, Morgan K, et al. Overfeeding rapidly induces leptin and insulin resistance. Diabetes. 2001;50:2786-91.

3. Ohannesian JP, Marco CC, Najm PS, et al. Small weight gain is not associated with development of insulin resistance in healthy, physically active individuals. Horm Metab Res. 1999;31:323-5.

4. Guidone C, Manco M, Valera-Mora E, et al. Mechanisms of recovery from type 2 diabetes after malabsorptive bariatric surgery. Diabetes. 2006;55:2025-31.

5. Reaven GM, Silvers A, Farquhar JW. Study of the relationship between plasma insulin concentration and efficiency of glucose uptake in normal and mildly diabetic subjects. Diabetes. 1970;19:571-8.

6. Shen SW, Reaven GM, Farquhar JW. Comparison of impedance to insulin-mediated glucose uptake in normal subjects and in subjects with latent diabetes. J Clin Invest. 1970;49:2151-60.

7. Pei D, Jones CN, Bhargava R, et al. Evaluation of octreotide to assess insulin-mediated glucose disposal by the insulin suppression test. Diabetologia. 1994;37:843-5.

8. van Dielen FM, Buurman WA, Hadfoune M, et al. Macrophage inhibitory factor, plasminogen activator inhibitor-1, other acute phase proteins, and inflammatory mediators normalize as a result of weight loss in morbidly obese subjects treated with gastric restrictive surgery. J Clin Endocrinol Metab. 2004;89:4062-8.

9. Mott DM, Lillioja S, Bogardus C. Overnutrition induced decrease in insulin action for glucose storage: in vivo and in vitro in man. Metabolism. 1986;35:160-5.

10. Dhindsa S, Tripathy D, Mohanty P, et al. Differential effects of glucose and alcohol on reactive oxygen species generation and intranuclear nuclear factor-kappaB in mononuclear cells. Metabolism. 2004;53:330-4. 
11. Mohanty P, Hamouda W, Garg R, et al. Glucose challenge stimulates reactive oxygen species (ROS) generation by leucocytes. J Clin Endocrinol Metab. 2000;85:2970-3.

12. Mohanty P, Ghanim H, Hamouda W, et al. Both lipid and protein intakes stimulate increased generation of reactive oxygen species by polymorphonuclear leukocytes and mononuclear cells. Am J Clin Nutr. 2002;75:767-72.

13. Houstis N, Rosen ED, Lander ES. Reactive oxygen species have a causal role in multiple forms of insulin resistance. Nature. 2006;440:944-8.

14. Rutkowski DT, Kaufman RJ. A trip to the ER: coping with stress. Trends Cell Biol. 2004;14:20-8.
15. Harding HP, Zhang $\mathrm{Y}$, Zeng $\mathrm{H}$, et al. An integrated stress response regulates amino acid metabolism and resistance to oxidative stress. Mol Cell. 2003;11:619-33.

16. Ozcan U, Cao Q, Yilmaz E, et al. Endoplasmic reticulum stress links obesity, insulin action, and type 2 diabetes. Science. 2004;306:457-61.

17. Chin-Chance C, Polonsky KS, Schoeller DA. Twenty-four-hour leptin levels respond to cumulative short-term energy imbalance and predict subsequent intake. J Clin Endocrinol Metab. 2000;85:2685-91.

18. Hansen EN, Torquati A, Abumrad NN. Results of bariatric surgery. Annu Rev Nutr. 2006;26:481-511. 